\title{
Transesophageal echocardiography probe shutdown in a patient with hyperthermia
}

\author{
Vandana Saluja, Gaganpal Singh, Chandrakant Pandey
}

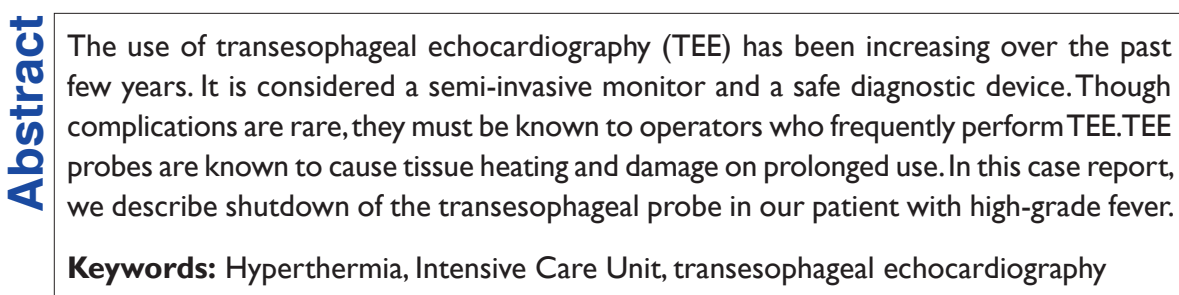

\section{Introduction}

Apart from use in operative cases and cardiac laboratories, transesophageal echocardiography (TEE) in now being increasingly used in critical care units. The complications with its use are primarily related to gastrointestinal, cardiovascular, and respiratory systems along with some miscellaneous problems related to probe insertion, drugs, and inexperience of the operator. ${ }^{[1]}$ TEE is routinely done in patients with fever, especially infective endocarditis. However, there has been no report of probe shutdown in such cases. Our case report does not describe a complication due to TEE per se, but a unique clinical situation, which has not been reported previously.

\section{Case Report}

A 55-year-old male, with chronic liver disease, long-standing diabetes mellitus, and obesity (body mass index of 30), was admitted to the Intensive Care Unit (ICU) with altered sensorium, upper gastrointestinal bleed, and

From:

Department of Anesthesiology and Critical Care, Institute of Liver and Biliary Sciences, New Delhi, 'Department of Cardiac Anesthesia and Critical Care,

Alchemist Hospitals, Gurgaon, Haryana, India

\section{Correspondence:}

Dr. Vandana Saluja, Department of Anesthesiology and Critical Care, Institute of Liver and Biliary Sciences, Sector D1, Vasant Kunj,

New Delhi - 110 070, India.

E-mail: vandypats@yahoo.co.in

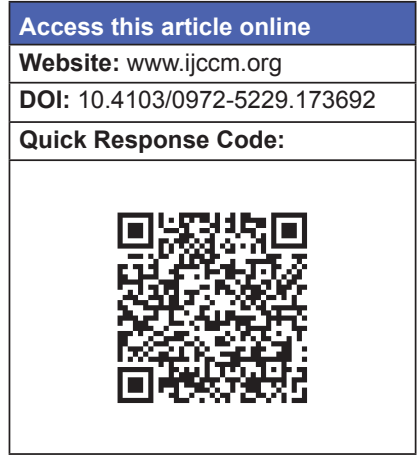

hemodynamic instability. His Child-Turcotte-Pugh score was seven. He was intubated and put on ventilatory support for airway protection. An upper gastrointestinal endoscopy showed bleeding from a gastric varix which was appropriately controlled. There were no esophageal varices. His hemoglobin was stabilized to $12 \mathrm{~g} \%$ after transfusion of packed red blood cells.

Despite control of bleed, the patient required rapid escalation of vasopressors over several hours. He had developed fever after $24 \mathrm{~h}$ of ICU admission. He developed a temperature of $39^{\circ} \mathrm{C}$ (axillary temperature) with circulatory shock and increasing lactate levels. His $24 \mathrm{~h}$ culture (blood, urine, and mini bronchoalveolar lavage) reports sent on ICU admission were sterile. He developed atrial fibrillation, which required cardioversion. His bedside echocardiogram showed a very poor window with a provisionally normal report.

This is an open access article distributed under the terms of the Creative Commons Attribution-NonCommercial-ShareAlike 3.0 License, which allows others to remix, tweak, and build upon the work non-commercially, as long as the author is credited and the new creations are licensed under the identical terms.

For reprints contact: reprints@ medknow.com

How to cite this article: Saluja V, Singh G, Pandey C. Transesophageal echocardiography probe shutdown in a patient with hyperthermia. Indian J Crit Care Med 2016;20:50-1. 
In view of long-standing diabetes mellitus, obesity, and poor transthoracic images, a bedside TEE was planned to rule out a cardiac cause of poor hemodynamics.

After appropriate consent, the transesophageal probe (MyLabTM 30Gold Esaote, TE 022) was inserted orally into the esophagus. It was examined physically for any defects before insertion. Within seconds of the probe insertion, the TEE monitor showed a rapid rise in temperature to $42.5^{\circ} \mathrm{C}$. The probe stopped functioning, indicating a high temperature. The examination was withheld and a cold saline lavage was given through the nasogastric tube to reduce the local temperature. The lavage reduced the local temperature down to $38^{\circ} \mathrm{C}$ after which examination was resumed. After obtaining images for $5 \mathrm{~min}$, there was a rise in temperature and the above procedure was repeated twice before we could satisfactorily complete the examination. The probe was re-examined after removal to rule out any mechanical damage.

\section{Discussion}

Esophageal heating and potential injury can occur from piezoelectric crystal vibration within the transesophageal probe tip or by direct tissue heating from absorbed ultrasound energy. ${ }^{[2,3]}$ Esophageal thermal injury has been reported in patients with severe atherosclerotic cardiovascular disease in whom the esophageal circulation was presumed to be compromised. ${ }^{[3]}$ Therefore, TEE probes have a thermocouple to monitor transducer tip temperature and an automatic shutdown mechanism when a critical preset temperature $\left(42-46^{\circ} \mathrm{C}\right)$ has been reached. ${ }^{[4]}$

TEE has been described in literature in patients with fever, most commonly in suspected bacterial endocarditis. ${ }^{[5,6]}$ The manufacturer guide does mention that the thermal limit can be reached in patients with fever.

However to our knowledge, this is the first case report describing shutdown of the probe due to increased body temperature of the patient.

In our patient, the probe stopped functioning immediately on entering the esophagus in the presence of high temperature and resumed functioning after a cold saline lavage. The stomach lies in close proximity to the liver and inferior vena cava, gastric lavage is a reasonable method to rapidly cool hyperthermic patients. A core temperature reduction of approximately $0.15^{\circ} \mathrm{C} / \mathrm{min}$ can be achieved using this method. ${ }^{[7]}$ We could complete our examination because of intermittent cold saline lavages which were given through the nasogastric tube.

It would have been ideal if we had anticipated such a problem before probe insertion. Active measures would have reduced the body temperature, and we could have completed our examination within a shorter period of time. We would recommend that TEE in a critically ill patient with fever should consider such a possibility and appropriate preventive measures should be taken.

Future attempts should be made for refinement of probe technology so that the machine is able to differentiate in temperature rise within the probe versus the surroundings.

\section{Financial support and sponsorship}

Nil.

\section{Conflicts of interest}

There are no conflicts of interest.

\section{References}

1. Mathur SK, Singh P. Transoesophageal echocardiography related complications. Indian J Anaesth 2009;53:567-74.

2. Urbanowicz JH, Kernoff RS, Oppenheim G, Parnagian E, Billingham ME, Popp RL. Transesophageal echocardiography and its potential for esophageal damage. Anesthesiology 1990;72:40-3.

3. Kharasch ED, Sivarajan M. Gastroesophageal perforation after intraoperative transesophageal echocardiography. Anesthesiology 1996;85:426-8

4. Savino JS, Weiss S. Safety of transesophageal echocardiography is still unclear. Anesthesiology 1990;73:366-7.

5. Fowler VG Jr., Li J, Corey GR, Boley J, Marr KA, Gopal AK, et al. Role of echocardiography in evaluation of patients with Staphylococcus aureus bacteremia: Experience in 103 patients. J Am Coll Cardiol 1997;30:1072-8.

6. Goland S, Shimoni S, Attali M, Somin M, Azoulai O, Caspi A, et al. Fatal ventricular arrhythmia as a complication of transesophageal echocardiography. Eur J Echocardiogr 2005;6:151-3.

7. Schraga ED, Kates LW. Cooling Techniques for Hyperthermia. Medscape Drugs and Diseases. Available from: http://www.emedicine. medscape.com/article/149546-overview. [Last updated on 2013 Apr 09]. 